\title{
Early Pulsed Dye Laser Treatment for Infantile Hemangiomas: An Open Study for 50 Japanese Infancies*
}

\author{
Hideki Endo", Naoki Oiso, Akira Kawada \\ Department of Dermatology, Kinki University Faculty of Medicine, Osaka-Sayama, Japan. \\ Email: "Hideki@sakai.med.kindai.ac.jp, naoiso@med.kindai.ac.jp, kawada@med.kindai.ac.jp
}

Received July $4^{\text {th }}, 2013$; revised August $5^{\text {th }}, 2013$; accepted August $13^{\text {th }}, 2013$

Copyright (C) 2013 Hideki Endo et al. This is an open access article distributed under the Creative Commons Attribution License, which permits unrestricted use, distribution, and reproduction in any medium, provided the original work is properly cited.

\begin{abstract}
Infantile hemangiomas, occurring at birth or during the first weeks of life, are benign vascular tumors with an initial proliferative phase and a later involutional phase. The massive proliferation on the key regions and unpredicted regression may threaten life. Thus, early management of infantile hemangiomas is necessary for affected infancies. Recent studies showed that propranolol for infantile hemangiomas had high efficacy for disappearance or reduction of infantile hemangiomas. However, a most recent study demonstrated existence of propranolol-resistant infantile hemangiomas. Therefore, we retrospectively evaluated efficacy of established early pulsed dye laser treatment for infantile hemangiomas in the 50 Japanese infancies which were applied in the period from 2000 to 2005, because our series included from the plaque subtype to the more proliferative tumor subtype. High efficacy in both subtypes suggests that early pulsed dye laser treatment can still be included as the first option for the mixed type of infantile hemangiomas and that pulsed dye laser treatment may be useful as the second line for the propranolol-resistant mixed type of infantile hemangiomas.
\end{abstract}

Keywords: Evaluation; Pulsed Dye Laser; Infantile Hemangioma; An Open Study; Color; Size; Texture

\section{Introduction}

Infantile hemangiomas (IH) are benign vascular tumors appearing at birth or during the first weeks of life [1-5]. $\mathrm{IH}$ are clinically classified as the superficial, the superficial and deep (mixed), and the deep types [2]. The mixed type has varied from the plaque subtype to the more proliferative tumor subtype. IH commonly have an initial proliferative phase and a later involutional phase [6]. Ulceration, bleeding and deformity may threaten life when the tumors proliferate massively, locate on the key regions or regress unpredictably [7]. Treatment during premature period is recommended to avoid permanent sequelae such as chromatosis telangiectasias and scarring [7]. Early pulsed dye laser treatment or systemic corticosteroid therapy has been applied for treatment of IH. Pulsed dye laser for IH has been shown to have high efficacy and low unexpected outcome $[8,9]$.

In 2008, Léauté-Labrèze et al. showed remarkable effectiveness of propranolol for IH [10]. In Europe and US, administration of propranolol is currently prevalent $[11$, 12]. However, a subgroup with propranolol-resistant IH

"Conflicts of interest: None.

\#Corresponding author. is recently reported [13]. Early pulsed dye laser treatment would be a next option for patients who had propranololresistant IH of the mixed type. We retrospectively summarized efficacy of early pulsed dye laser treatment from 2000 to 2005 in 50 Japanese infancies with the mixed type of $\mathrm{IH}$, because our series included not only the plaque subtype but also the tumor subtype.

\section{Methods}

We retrospectively evaluated efficacy of early pulsed dye laser treatment for the mixed type of IH in 50 (16 males and 34 females) Japanese infancies ranging from 1 to 12 month old. In this series, all cases were applied in the period from 2000 to 2005 . We further sub-classified into the plaque and the tumor subtypes according to the clinical phenotype. The typical plaque subtype was shown in (Figure 1(a)). The plaque subtype was characterized by faint vertical proliferation. The typical tumor subtypes were shown in (Figures 2(a) and 3(a)). The tumor subtype was manifested with noticeable vertical proliferation. We applied a $585 \mathrm{~nm}$-pulsed dye laser with 1 to 8 periodical exposures, and estimated effectiveness of color, size and texture. The representative results were shown in (Figures 1(b), 2(b) and 3(b)). 


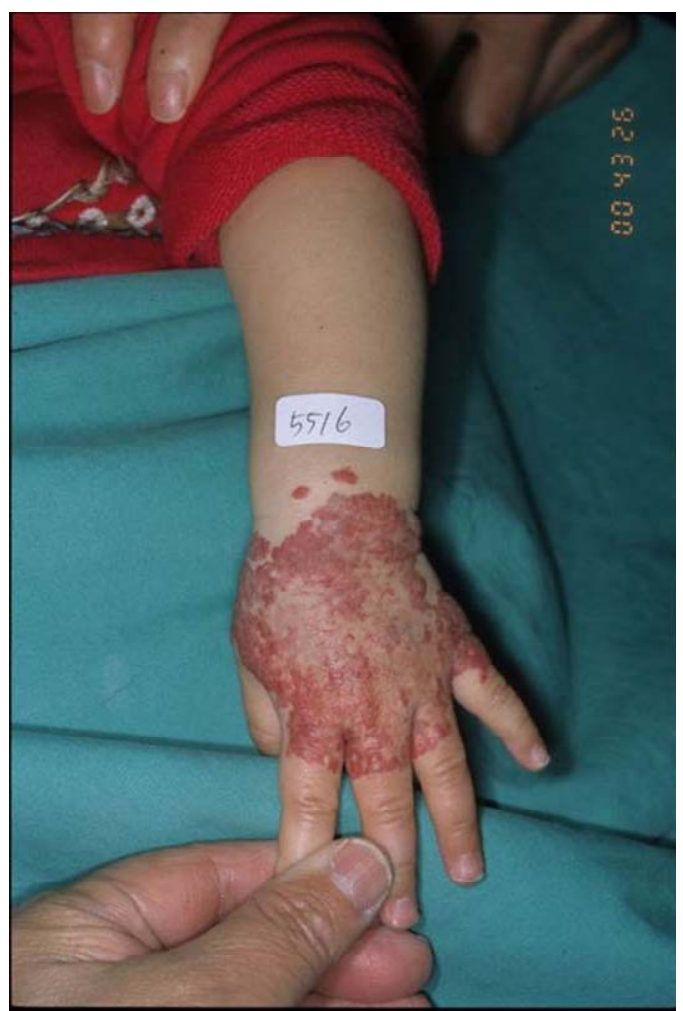

(a)

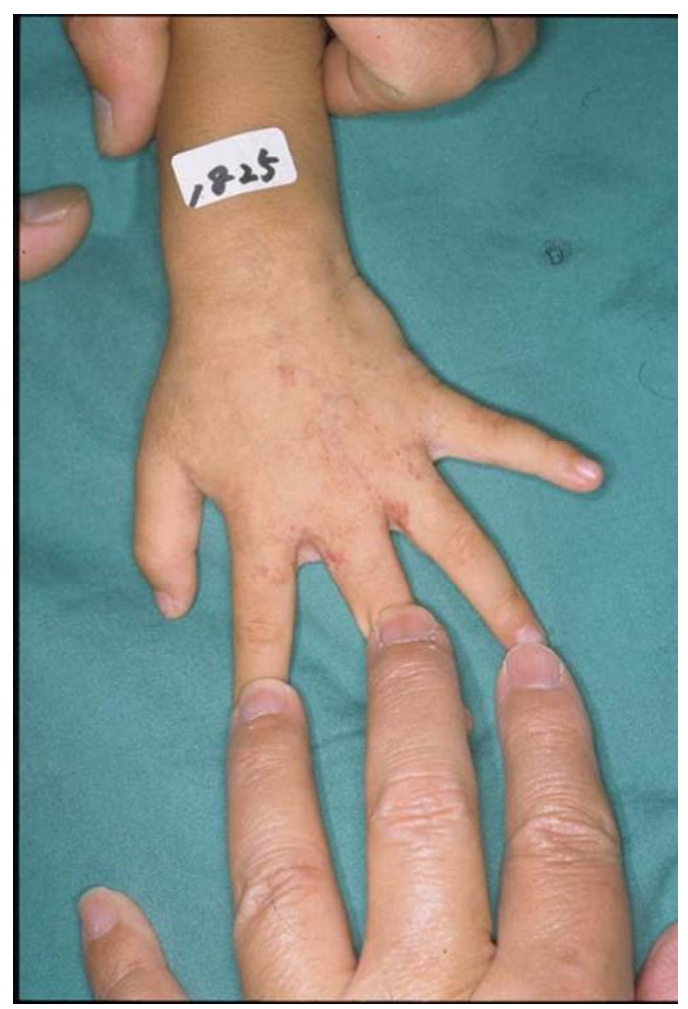

(b)

Figure 1. The plaque subtype: clinical pictures of the female case 9 on the left hand at the age of 12 months. Excellent improvement was achieved by four times of pulsed dye laser treatment. (a) Pre-irradiation; (b) Post-irradiation.

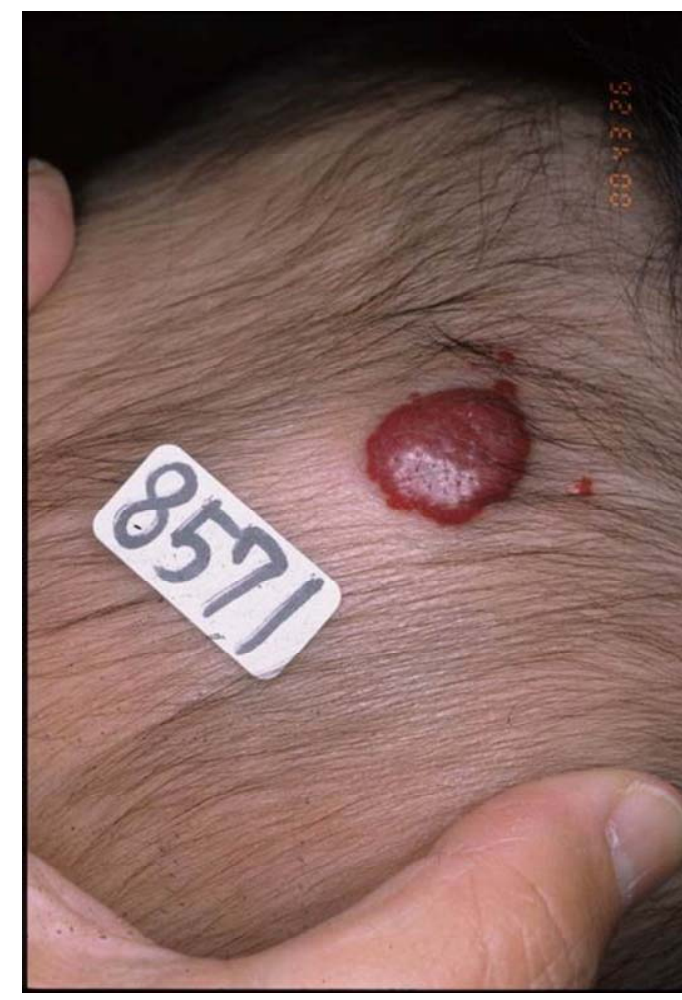

(a)

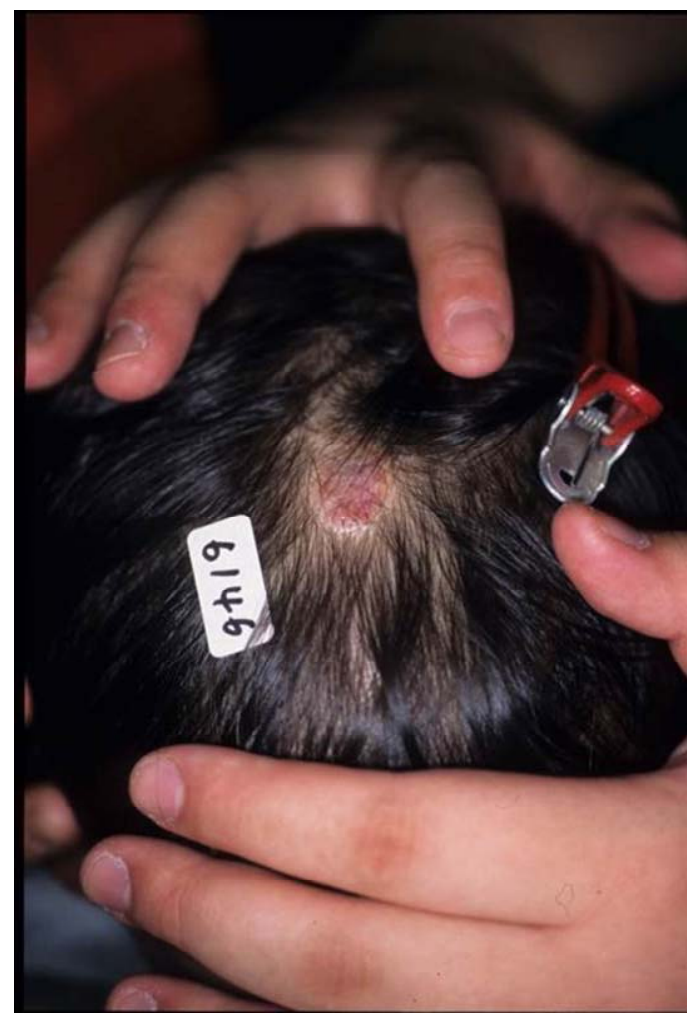

(b)

Figure 2. The tumor subtype: clinical pictures of the female case 2 on the head at the age of 5 months. Excellent improvement was achieved by six times of pulsed dye laser treatment. (a) Pre-irradiation; (b) Post-irradiation. 


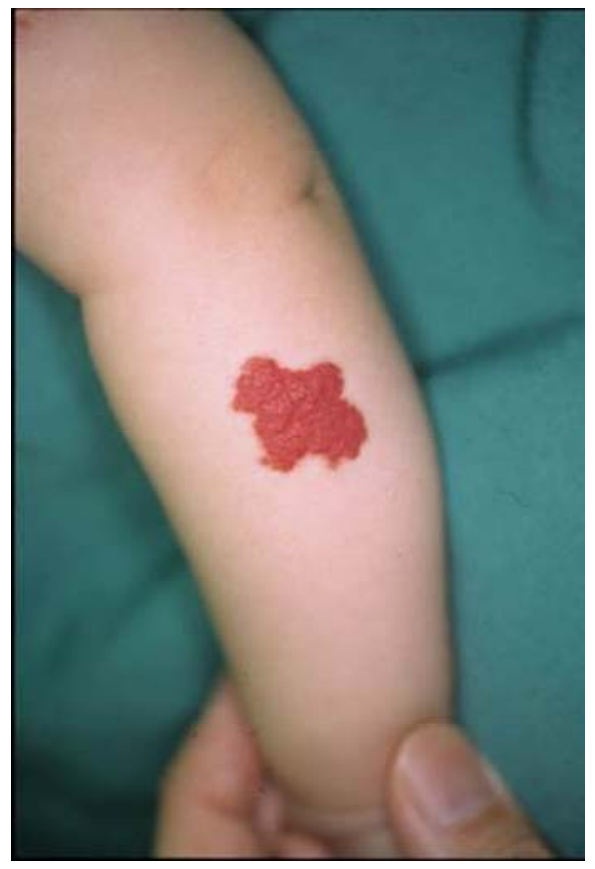

(a)

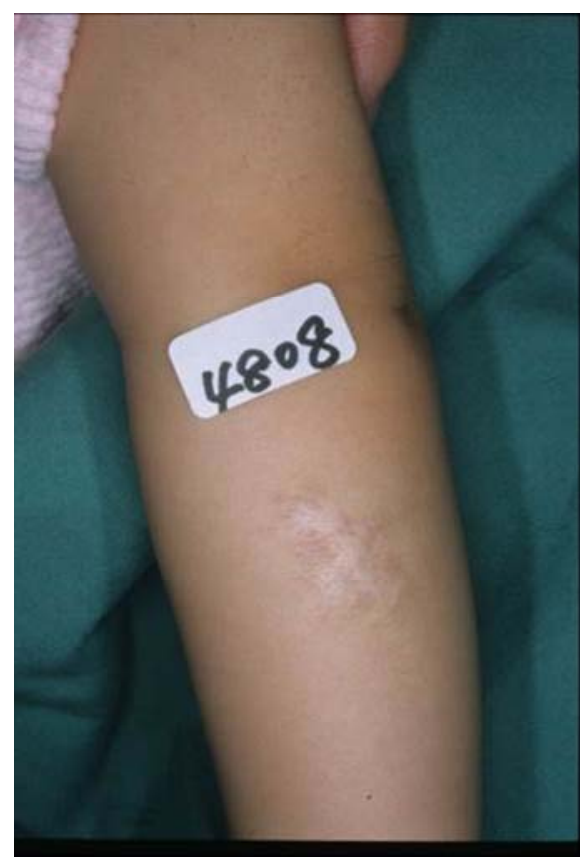

(b)

Figure 3. The tumor subtype: clinical pictures of the female case 18 on the left upper limb at the age of 6 months. Excellent improvement was achieved by three times of pulsed dye laser treatment. (a) Pre-irradiation; (b) Post-irradiation.

We used PhotogenicaV ${ }^{\circledR}$ (Cynosure K.K., Tokyo, Japan) emitting pulsed light at a wavelength of $585 \mathrm{~nm}$ with pulse duration of 300 to $500 \mu \mathrm{sec}$, and fluorescence of 6.0 to $7.0 \mathrm{~J} / \mathrm{cm}$ with a $5 \mathrm{~mm}$ spot size. In this study, application was unified in a pulse width of $450 \mu \mathrm{sec}$. At each session, one to seven shots were delivered accord- ing to the size of $\mathrm{IH}$.

The outcomes were objectively assessed by two independent observers using side-by-side comparisons of clinical photographs taken before and after treatment. Photographs after treatment were taken after three months from the last session. Effectiveness was graded using four groups as excellent improvement (more than 75 percent clearing), moderate improvement (from 50 to less than 75 percent clearing), slight improvement (from 25 to less than 50 percent clearing), and no-alteration (less than 25 percent clearing).

\section{Results}

Results in each case were summarized in Table 1: excellent improvement in $28(56.0 \%)$ of 50 affected infancies, moderate improvement in $19(38.0 \%)$ and slight improvement in $3(6.0 \%)$. The effectiveness in the plaque subtype and the tumor subtype was summarized in Table 2. The plaque subtype resulted in excellent improvement in $13(68.4 \%)$ of 19 affected infancies, moderate improvement in $6(31.6 \%)$ and no slight improvement. The tumor subtype showed excellent improvement in 15 (48.4\%) of 31 affected infancies, moderate improvement in $13(41.9 \%)$ and slight improvement in $3(9.7 \%)$.

\section{Discussion}

Pulsed dye laser treatment gives excellent therapeutic results in most types of superficial small-vessel lesions such as portwine stains [14,15], IH [8,9], telangiectasias and other angioma. The risk occurring scar is rare, because energy from the pulsed dye laser is absorbed into the vessels in a rather specific manner.

The pulsed dye laser utilizes theories of selective photothermolysis [16]. The laser emits a monochromatic light which wavelength corresponds to the absorption peak of hemoglobin, leading to selective photothermolysis of cutaneous blood vessels [16]. The pulsed dye laser can produce highly selective cutaneous microvascular damage by choosing an appropriate wavelength and energy density within exposure duration of the thermal relaxation time of the target structure.

The results in our study showed excellent efficacy in the plaque subtype as well as in the tumor subtype, even though the plaque subtype showed more excellent response. Our study confirmed that early treatment with pulsed dye laser for IH recovered skin color, prevented more proliferation of the size and change of the texture. This study evidenced that the tumor subtype could even be managed with pulsed dye laser as commonly shown as the plaque subtype $[8,9]$.

Our results suggest that early pulsed dye laser treatment for IH can still be included as the first option for management for the mixed type of IH. The high efficacy 
Table 1. Cases: results of early pulsed dye laser treatment for the mixed type of infantile hemangiomas.

\begin{tabular}{|c|c|c|c|c|c|c|c|c|c|c|}
\hline Case & Sex & Month & Site & Type & Fluence & Times & Color & Size & Texture & Improved \\
\hline 1 & $\mathrm{~F}$ & 2 & Left ear & plaque & 6.5 & 2 & excellent & excellent & excellent & excellent \\
\hline 2 & M & 5 & head & tumor & 6.5 & 6 & moderate & excellent & excellent & excellent \\
\hline 3 & M & 4 & left upper limb & tumor & 6.5 & 5 & excellent & excellent & excellent & excellent \\
\hline 5 & $\mathrm{~F}$ & 5 & right chest & tumor & 6.5 & 1 & excellent & excellent & excellent & excellent \\
\hline 6 & $\mathrm{~F}$ & 1 & abdomen & tumor & 6.5 & 3 & excellent & moderate & excellent & excellent \\
\hline 7 & $\mathrm{~F}$ & 3 & right lower limb & tumor & 6.5 & 4 & excellent & excellent & excellent & excellent \\
\hline 8 & $\mathrm{~F}$ & 12 & left lower limb & tumor & 6.5 & 2 & moderate & moderate & excellent & moderate \\
\hline 10 & $\mathrm{~F}$ & 8 & abdomen & tumor & 6.5 & 7 & excellent & excellent & excellent & excellent \\
\hline 11 & M & 2 & left upper limb & tumor & 6.5 & 3 & excellent & excellent & excellent & excellent \\
\hline 12 & M & 3 & right knee & tumor & 6.5 & 7 & excellent & excellent & excellent & excellent \\
\hline 13 & $\mathrm{~F}$ & 4 & neck & plaque & 6.5 & 4 & excellent & excellent & excellent & excellent \\
\hline 14 & $\mathrm{~F}$ & 4 & face & plaque & 6.5 & 2 & moderate & excellent & moderate & moderate \\
\hline 15 & M & 11 & back & tumor & 6.5 & 1 & moderate & excellent & excellent & moderate \\
\hline 16 & $\mathrm{~F}$ & 2 & nose & plaque & 6.5 & 4 & excellent & excellent & excellent & excellent \\
\hline 17 & M & 1 & neck & tumor & 6.5 & 4 & excellent & moderate & excellent & moderate \\
\hline 18 & M & 6 & left upper limb & tumor & 6.5 & 3 & excellent & excellent & excellent & excellent \\
\hline 20 & $\mathrm{~F}$ & 4 & left foot & tumor & 6.5 & 3 & moderate & moderate & excellent & moderate \\
\hline 21 & $\mathrm{~F}$ & 7 & face & tumor & 6.5 & 1 & moderate & excellent & excellent & moderate \\
\hline 22 & $\mathrm{~F}$ & 3 & left chest & tumor & 6.5 & 3 & excellent & slight & slight & slight \\
\hline 23 & $\mathrm{~F}$ & 4 & left upper limb & tumor & 6.5 & 1 & excellent & moderate & moderate & moderate \\
\hline 24 & $\mathrm{~F}$ & 12 & back & tumor & 6.5 & 1 & excellent & excellent & excellent & excellent \\
\hline 25 & $\mathrm{~F}$ & 6 & nose & plaque & 6.5 & 2 & excellent & excellent & moderate & excellent \\
\hline 26 & M & 9 & head & tumor & 6.5 & 3 & moderate & moderate & excellent & moderate \\
\hline 27 & $\mathrm{~F}$ & 11 & back & tumor & 6.5 & 3 & excellent & excellent & excellent & excellent \\
\hline 28 & $\mathrm{~F}$ & 4 & head & tumor & 6.5 & 3 & excellent & Moderate & moderate & moderate \\
\hline 29 & $\mathrm{~F}$ & 4 & abdomen & plaque & 6.5 & 2 & excellent & excellent & moderate & excellent \\
\hline 30 & $\mathrm{~F}$ & 3 & face & tumor & 6.5 & 8 & excellent & slight & slight & slight \\
\hline 31 & $\mathrm{~F}$ & 4 & hip & plaque & 6.5 & 2 & excellent & excellent & excellent & excellent \\
\hline 32 & M & 5 & left lower limb & tumor & 6.5 & 6 & excellent & moderate & moderate & moderate \\
\hline 33 & M & 3 & face & plaque & 6.5 & 2 & excellent & excellent & excellent & excellent \\
\hline 34 & M & 2 & left upper limb & plaque & 6.5 & 3 & excellent & excellent & excellent & excellent \\
\hline 35 & $\mathrm{~F}$ & 12 & right lower limb & tumor & 6.5 & 5 & moderate & slight & slight & slight \\
\hline 36 & $\mathrm{~F}$ & 10 & left lower limb & plaque & 6.5 & 2 & excellent & moderate & excellent & excellent \\
\hline
\end{tabular}




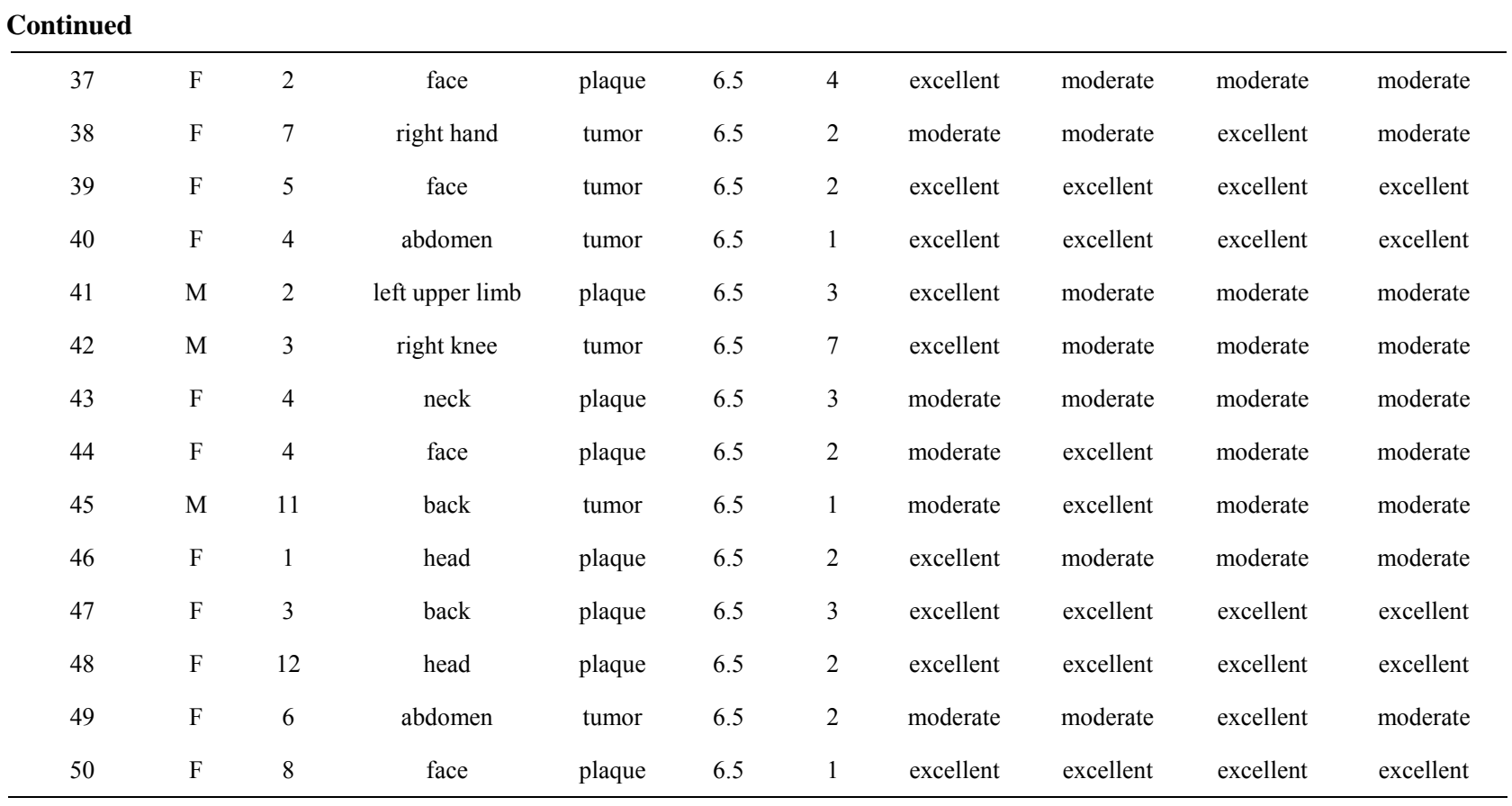

Table 2. Summary: results of early pulsed dye laser treatment for the mixed type of infantile hemangiomas.

\begin{tabular}{cccc}
\hline & Excellent & Moderate & Slight \\
\hline plaque type (19) & 13 & 6 & 0 \\
tumor type (31) & 15 & 13 & 3 \\
total (50) & 28 & 19 & 3 \\
\hline
\end{tabular}

for the tumor subtype of the mixed IH in this study implies that pulsed dye laser treatment may be effective as the second line for the propranolol-resistant mixed type of IH.

\section{REFERENCES}

[1] N. Oiso, M. Kimura, S. Kawara and A. Kawada, "Clinical, Dermoscopic, and Histopathologic Features in a Case of Infantile Hemangioma without Proliferation," Pediatric Dermatology, Vol. 28, No. 1, 2011, pp. 66-68. doi:10.1111/j.1525-1470.2010.01363.x

[2] N. Oiso and A. Kawada, "The Dermoscopic Features in Infantile Hemangioma," Pediatric Dermatology, Vol. 28, No. 5, 2011, pp. 591-593. doi:10.1111/j.1525-1470.2011.01385.x

[3] M. Miyake, N. Oiso and A. Kawada. "Dermoscopic Appearances in the Superficial and Deep Type of Infantile Hemangioma," Journal of Cosmetics, Dermatological Sciences and Applications, Vol. 2012, No. 2, 2012, pp. 212-213. doi:10.4236/jcdsa.2012.23038

[4] K. G. Chiller, D. Passaro and I. J. Frieden, "Hemangiomas of Infancy: Clinical Characteristics, Morphologic Subtypes, and Their Relationship to Race, Ethnicity, and Sex," Archive of Dermatology, Vol. 138, No. 12, 2002, pp. 1567-1576. doi:10.1001/archderm.138.12.1567

[5] F. Corella, X. Garcia-Navarro, A. Ribe, A. Alomar and E. Baselga, "Abortive or Minimal-Growth Hemangiomas: Immunohistochemical Evidence That They Represent True Infantile Hemangiomas," Journal of American Academy of Dermatology, Vol. 58, No. 4, 2008, pp. 685-690. doi:10.1016/j.jaad.2007.08.007

[6] A. N. Haggstrom, B. A. Drolet, E. Baselga, S. L. Chamlin, M. C. Garzon, K. A. Horii, A. W. Lucky, A. J. Mancini, D. W. Metry, B. Newell, A. J. Nopper and I. Frieden, "Prospective Study of Infantile Hemangiomas: Clinical Characteristics Predicting Complications and Treatment," Pediatrics, Vol. 118, No. 3, 2006, pp. 882-887. doi:10.1542/peds.2006-0413

[7] L. Zhang, H. M. Mai, J. Zheng, J. W. Zheng, Z. G. Chen, Y. A. Wang, Z. P. Qin, K. L. Li and W. E. Yuan, "Preliminary Study on Plasma RPN Concentration of Patients with Infantile Hemangioma Treated with Propranolol," International Journal of Clinical and Experimental Medicine, Vol. 6, No. 5, 2013, pp. 342-345.

[8] S. Admani, A. C. Krakowski, J. S. Nelson, L. F. Eichenfield and S. F. Friedlander, "Beneficial Effects of Early Pulsed Dye Laser Therapy in Individuals with Infantile Hemangiomas," Dermatologic Surgery, Vol. 38, No. 10, 2012, pp. 1732-1738. doi:10.1111/j.1524-4725.2012.02487.x

[9] Y. K. Tay and S. K. Tan, "Treatment of Infantile Hemangiomas with the 595-nm Pulsed Dye Laser Using Different Pulse Widths in an Asian Population," Lasers in Surgery and Medicine, Vol. 44, No. 2, 2012, pp. 93-96. doi: $10.1002 / 1 \mathrm{sm} .21159$

[10] C. Léauté-Labrèze, E. D. de la Roque, T. Hubiche, F. Boralevi, J. B. Thambo and A. Taïeb, "Propranolol for Severe Hemangiomas of Infancy," The New England Journal of Medicine, Vol. 358, No. 24, 2008, pp. 2549- 
2651. doi:10.1056/NEJMc0708819

[11] V. Mendiratta, B. Varghese, R. Chander, A. Parakh and R. S. Solanki, "Successful Management of Airway Hemangioma with Propranolol," International Journal of Dermatology, Vol. 52, No. 6, 2013, pp. 750-752. doi:10.1111/j.1365-4632.2012.05752.x

[12] B. A. Drolet, P. C. Frommelt, S. L. Chamlin, A. Haggstrom, N. M. Bauman, Y. E. Chiu, R. H. Chun, M. C. Garzon, K. E. Holland, L. Liberman, S. MacLellan-Tobert, A. J. Mancini, D. Metry, K. B. Puttgen, M. Seefeldt, R. Sidbury, K. M. Ward, F. Blei, E. Baselga, L. Cassidy, D. H. Darrow, S. Joachim, E. K. Kwon, K. Martin, J. Perkins, D. H. Siegel, R. J. Boucek and I. J. Frieden, "Initiation and Use of Propranolol for Infantile Hemangioma: Report of a Consensus Conference," Pediatrics, Vol. 131, No. 1, 2013, pp. 128-140. doi:10.1542/peds.2012-1691

[13] S. Caussé, H. Aubert, M. Saint-Jean, E. Puzenat, A. C. Bursztejn, C. Eschard, E. Mahé, A. Maruani, J. Mazereeuw-Hautier, I. Dreyfus, J. Miquel, C. Chiaverini, O.
Boccara, S. Hadj-Rabia, J. F. Stalder, S. Barbarot; The Groupe de Recherche Clinique en Dermatologie Pédiatrique, "Propranolol-Resistant Infantile Hemangiomas," British Journal of Dermatology, Vol. 169, No. 1, 2013, pp. 125-129.

[14] S. Sommer S, D. C. Seukeran and R. A. Sheehan-Dare, "Efficacy of Pulsed Dye Laser Treatment of Port Wine Stain Malformations of the Lower Limb," British Journal of Dermatology, Vol. 149, No. 4, 2003, pp. 770-775. doi:10.1046/j.1365-2133.2003.05467.x

[15] S. W. Lanigen and S. M. Taibjee, "Recent Advances in Laser Treatment of Port-Wine Stains," British Journal of Dermatology, Vol. 151, No. 3, 2004, pp. 527-533. doi:10.1111/j.1365-2133.2004.06163.x

[16] R. R. Anderson and J. A. Parrish, "Selective Photothemolysis: Precise Microsurgery by Selective Absorption of Pulsed Radiation," Science, Vol. 220, No. 4596, 1983, pp. 524-527. doi:10.1126/science.6836297 